\title{
Dietary Salt Intake and Cardiovascular Disease: Summarizing the Evidence
}

\author{
Murielle Bochud, $\mathrm{MD}, \mathrm{PhD},{ }^{1}$ \\ Pedro Marques-Vidal, MD, $\mathrm{PhD},{ }^{1}$ \\ Michel Burnier, MD, ${ }^{2}$ \\ Fred Paccaud, MD, $\mathrm{MSc}^{1}$
}

\begin{abstract}
We present a narrative review of the literature linking dietary salt intake with cardiovascular health outcomes in humans and list the tools and strategies to reduce salt intake at the population level. There is a strong agreement among experts that dietary salt intake should be reduced, targeting average population levels less than $5 \mathrm{~g}$ per day. The main aim of this reduction is a decline in cardiovascular morbidity and mortality. Experimental data clearly show that reducing salt intake lowers blood pressure. Considering that high blood pressure is a major cardiovascular risk factor, this provides indirect evidence that salt reduction should improve cardiovascular health. ${ }^{1}$ There is also recent direct evidence that reducing salt intake reduces the incidence of cardiovascular disease. Direct evidence linking reduction in salt intake with decreased overall and cardiovascular mortality is more limited and disputed and the data for stroke are inconsistent. Thus, there is a debate on the quality and nature of the available evidence, particularly on the magnitude of the benefit provided by the achievable reduction in salt intake. Yet, there are no known deleterious consequences of the proposed reduction in salt intake. Several countries have adopted policies aiming at reducing salt intake in the general population. The relevant tools and strategies are directed to both the food industry and the consumers. At the industry level, the most efficient measure is legislation on the salt content of selected foods, an approach much more (cost) effective than voluntary reductions. None of the interventions aiming at reducing salt intake has been rigorously evaluated. In view of recurrent controversies, any intervention in this field should be accompanied by an appropriate monitoring and evaluation program.
\end{abstract}

Keywords: Salt, mortality, cardiovascular disease, sodium

\footnotetext{
${ }^{1}$ Institute of Social and Preventive Medicine, University Hospital and University of Lausanne, Route de la Corniche 2, 1066 Epalinges, Switzerland.

${ }^{2}$ Service of Nephrology, Lausanne University Hospital, 1005 Lausanne, Switzerland.
}

Corresponding Author Contact Information: Murielle Bochud at Murielle.Bochud@chuv. ch; Institute of Social and Preventive Medicine, Bâtiment Biopôle 1, Route de la Corniche 2, CH-1066 Epalinges, Switzerland. 
Recommended Citation: Bochud M, Marques-Vidal P, Burnier M, Paccaud F. Dietary salt intake and cardiovascular disease: summarizing the evidence. Public Health Reviews. 2012;33:530-52.

\section{INTRODUCTION}

The purpose of this narrative review is to summarize the existing literature linking dietary salt intake* with cardiovascular health outcomes in humans, taking into account the level of evidence in a context of recurrent controversies (Table 1). This review does not cover studies performed in hospital settings with patients. A further purpose is to list the possible tools and strategies to reduce salt intake at the global level.

\section{Table 1}

Cardiovascular health outcomes

that have been associated with high dietary salt intake in humans

\begin{tabular}{l|c|c}
\hline \multicolumn{1}{c|}{ Health outcome } & Direction & Strength of the evidence \\
\hline High blood pressure and Hypertension & $\uparrow$ & +++ \\
\hline Cardiovascular disease events & $\uparrow$ & +++ \\
\hline Cardiovascular mortality & $\uparrow$ & + \\
\hline Overall mortality & $\uparrow$ & $(+)$ \\
\hline Stroke & $\uparrow$ & $(+)$ \\
\hline Left-ventricular hypertrophy & $\uparrow$ & $(+)$ \\
\hline
\end{tabular}

+++ strong evidence (experimental data in form of multiple randomized controlled trials), ++ convincing evidence (other experimental data with consistent results), + moderate evidence (limited experimental data), (+) some evidence (observational data).

The World Health Organisation (WHO) recommends an average population salt intake of less than $5 \mathrm{~g}$ per day. ${ }^{2}$ Following technical meetings on July 1-2, 2010 in London and in October 2012 in Canada, the WHO published a report entitled "Creating an enabling environment for population-based salt reduction strategies". ${ }^{3}$ Several countries have adopted policies aiming at reducing dietary salt intake in the general population, such as Finland, France, UK, Japan, Australia and New Zealand. ${ }^{4}$

\footnotetext{
* Salt stands here for Sodium chloride $(\mathrm{NaCl})$. Prevention campaigns discussed in this paper are related only to sodium.
} 
Yet, the rationale for lowering dietary salt intake at the population level is still being debated in the scientific literature, which has been ongoing for many years now. ${ }^{5}$ The controversy has been revived by recent publications, notably a prospective study showing that low baseline urinary sodium excretion was associated with higher cardiovascular mortality. ${ }^{6}$ However, the observational nature of this study limits the strength of this evidence.

Salt intake influences cardiovascular morbidity and mortality mainly because of its positive association with blood pressure ${ }^{7}$ (Table 2). Hypertension (high blood pressure) is a major modifiable cardiovascular risk factor that affects one in four adults worldwide and is responsible for a high burden of disease in high-, middle- and low-income countries. A systematic Cochrane review by Taylor, et al. on the effects of randomized controlled trials of at least six months duration showed that reducing dietary salt intake led to a non-significant decrease in cardiovascular morbidity and mortality. Taylor, et al. concluded that "there is still insufficient power to exclude clinically important effects of reduced dietary salt on mortality or cardiovascular morbidity in normotensive or hypertensive populations.." $\mathrm{A}$ re-analysis including six trials (but excluding the heart failure trial) showed that reduced dietary salt intake was associated with non-significant reductions in all-cause mortality (4\% to 10\%) and cardiovascular mortality (31\%) and a significant reduction in cardiovascular events (20\%). ${ }^{8}$ Even when looking at the same set of data, experts appear to reach different conclusions. ${ }^{7,8}$ This probably reflects the fact that available data are insufficient to produce undisputable conclusions. Two population-based interventional studies at the level of two cities have been performed: a Portuguese study provides evidence that a population strategy to reduce salt intake was able to lower blood pressure ${ }^{9}$ and a Belgian study found no effect of such intervention. ${ }^{10}$ Here again results are inconclusive.

By contrast, recent public health reports highlighted that reduction in dietary salt intake at the population level is one of the most cost-effective public health strategies worldwide. ${ }^{11,12}$

The purpose of this narrative review is to summarize the existing literature linking dietary salt intake with cardiovascular health outcomes in humans, taking into account the level of evidence in a context of recurrent controversies. A further purpose is to list the possible tools and strategies to reduce the salt intake at the global level. 


\section{PHYSIOLOGICAL NEEDS IN SALT INTAKE}

A minimum daily sodium intake is necessary for essential physiological functions. The recommended minimal daily sodium intake is $550 \mathrm{mg} / \mathrm{day}$, which corresponds to $1.5 \mathrm{~g}$ of salt $(\mathrm{NaCl})$ per day. It is estimated that adolescents and adults need a minimum amount of $500 \mathrm{mg}$ of sodium and $850 \mathrm{mg}$ of chloride per day, which corresponds to $1.3 \mathrm{~g}$ of salt per day. The levels of dietary salt intake currently consumed in most countries worldwide are much higher and well above physiological needs. ${ }^{13}$

\section{DIETARY SALT INTAKE AND BLOOD PRESSURE: A SHORT HISTORICAL PERSPECTIVE}

As early as the beginning of the $20^{\text {th }}$ century, Ambard and Beaujard recognized the role of dietary salt restriction in lowering blood pressure in humans. ${ }^{14}$ In the 1920s, Allen demonstrated the effectiveness of salt restriction in the treatment of hypertension and suggested that salt restriction at the population level would reduce cardiovascular morbidity and mortality. ${ }^{15}$ In the 1940s, Kempner found that a rice-fruit diet very low in salt was able to lower blood pressure in severely hypertensive patients. ${ }^{16}$ In the 1960s, Dahl was the first to report a positive association between dietary salt intake and the prevalence of hypertension across populations. ${ }^{17}$ In the 1970s, Froment. et al. conducted an ecologic study (based on published data) that analysed urinary sodium excretion and blood pressure across 28 populations: higher blood pressure and steeper age-related blood pressure were positively associated with urinary sodium excretion, a proxy for dietary salt intake. ${ }^{18}$ In the 1980 s, the INTERSALT study showed that populations with low dietary salt intakes (i.e., less than $3 \mathrm{~g} / 24 \mathrm{~h}$ or $1.1 \mathrm{~g}$ of sodium $/ 24 \mathrm{~h}$ ) experience a lower blood pressure increase with age and that the increase in systolic blood pressure with age was positively associated to dietary salt intake. ${ }^{19}$ This likely reflects the association of aging with increased blood pressure sensitivity to salt. In the 1990s, an overview of data collected for 47,000 non-African subjects from 24 communities confirmed the positive association between blood pressure and urinary sodium excretion across and within populations, and the strengthening of this association with age. ${ }^{1,20}$ In the 2000s, in the INTERMAP study, the blood pressure difference between Northern and Southern China, was found to be partly due to dietary salt intake. ${ }^{21}$ 


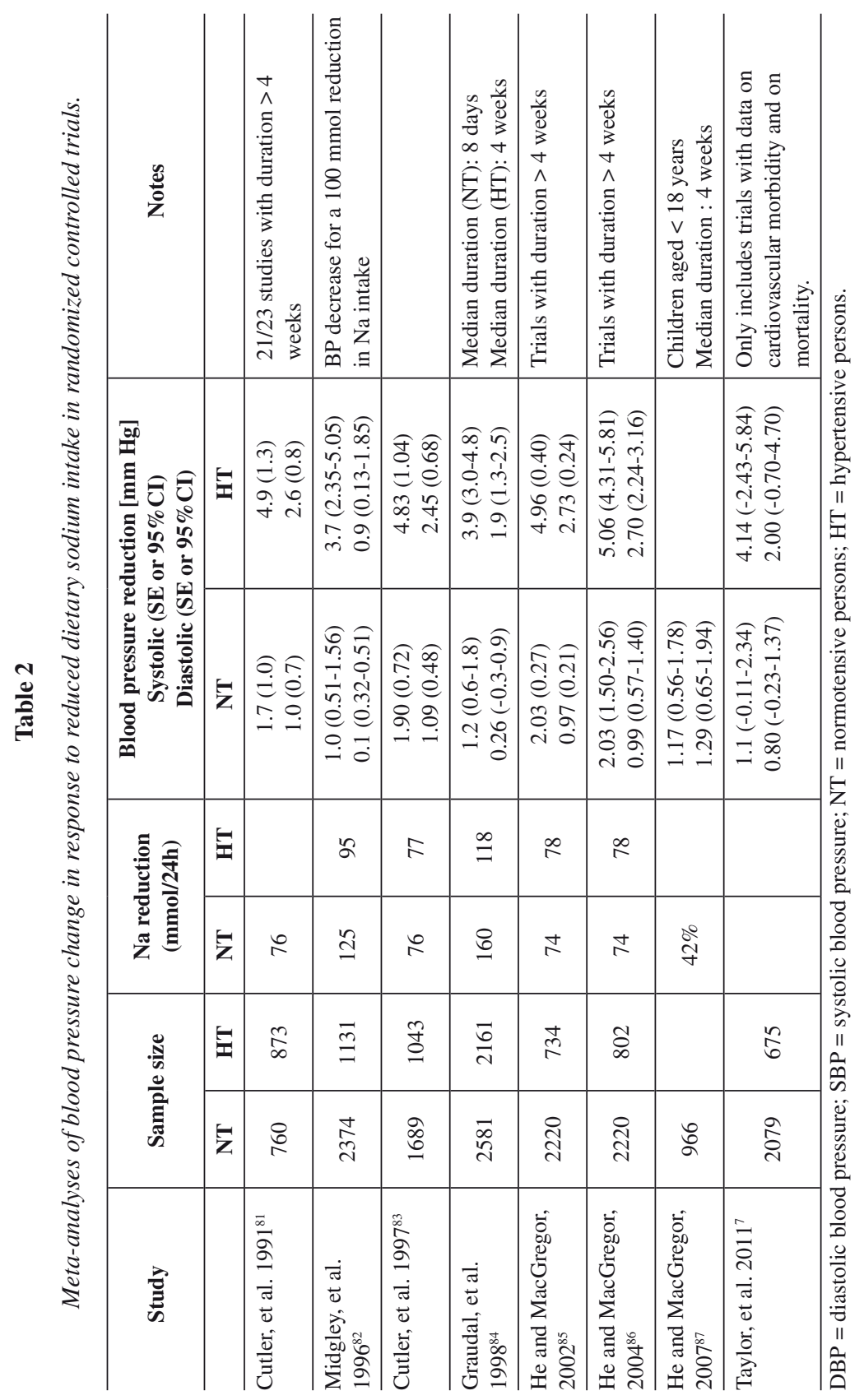


In the past 30 years, a large number of randomized controlled trials have analyzed the effect of reducing salt intake on blood pressure. Table 2 summarises the results of meta-analyses of these randomized controlled trails. Most trials explored the effect of short-term salt reduction (usually a few weeks). Sodium reductions of 70 to $100 \mathrm{mmol}$ (i.e., 4.1 to $5.9 \mathrm{~g}$ of salt) significantly reduce systolic/diastolic blood pressure in hypertensive (i.e., about 3-5/1-2 $\mathrm{mm} \mathrm{Hg}$, respectively) and in normotensive people (i.e., about $1-2 / 0-1 \mathrm{~mm} \mathrm{Hg}$, respectively). Such small reductions are expected, if sustained and applied to the general population, to lead to a substantial reduction in cardiovascular events.

\section{DIETARY SALT INTAKE AND BLOOD PRESSURE: THE MECHANISMS}

It is now widely recognized that an alteration in sodium handling by the kidney plays a crucial role in the pathogenesis of all forms of hypertension, although recent findings suggest that new molecular mechanisms in the skin could play an important role as well. ${ }^{22}$ Considerable debate exists with respect to the precise mechanisms that lead to primary hypertension and to blood pressure sensitivity to salt. By describing the relationship between systemic blood pressure and sodium balance, Guyton has demonstrated the key role of water and sodium excretion by the kidneys in the long-term regulation of blood pressure. ${ }^{23-25}$ Kimura and Brenner ${ }^{26}$ separated forms of secondary hypertension into sodium-sensitive and sodium-resistant. More recently, Johnson and colleagues ${ }^{27,28}$ have hypothesised that, over time, hypertension may shift from an initially salt-resistant to a subsequent saltsensitive type upon the accumulation of subtle renal injury. Johnson and colleagues proposed a unifying pathway for the pathogenesis of hypertension (and salt-sensitive hypertension) that combines many of the previously formulated hypotheses ${ }^{29}$ : salt-sensitivity likely results from an imbalance between vasoconstrictors (renin-angiotensin-aldosteron system and the sympathetic nervous system) and vasodilators (nitric oxide and the kallikrein-kinin system), in parallel with substances and mechanisms leading to progressive renal glomerular and/or tubular injuries. Additional observations that strengthen the view that sodium plays a key role in blood pressure control are that (i) almost all rare monogenic forms of hypertension are salt sensitive ${ }^{30}$ and (ii) all blood pressure candidate genes identified so far are either directly or indirectly associated with renal sodium handling in humans. ${ }^{31}$ 


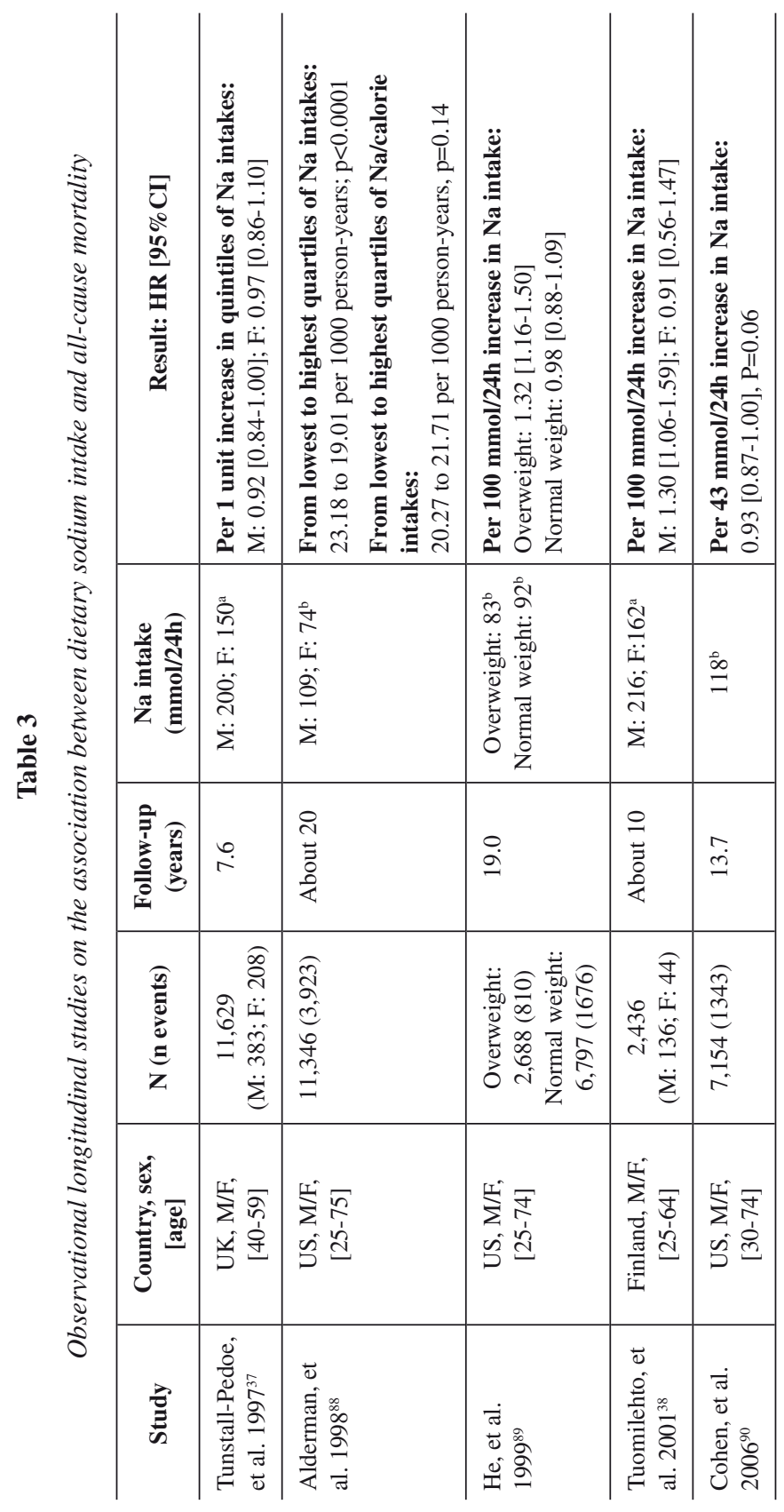




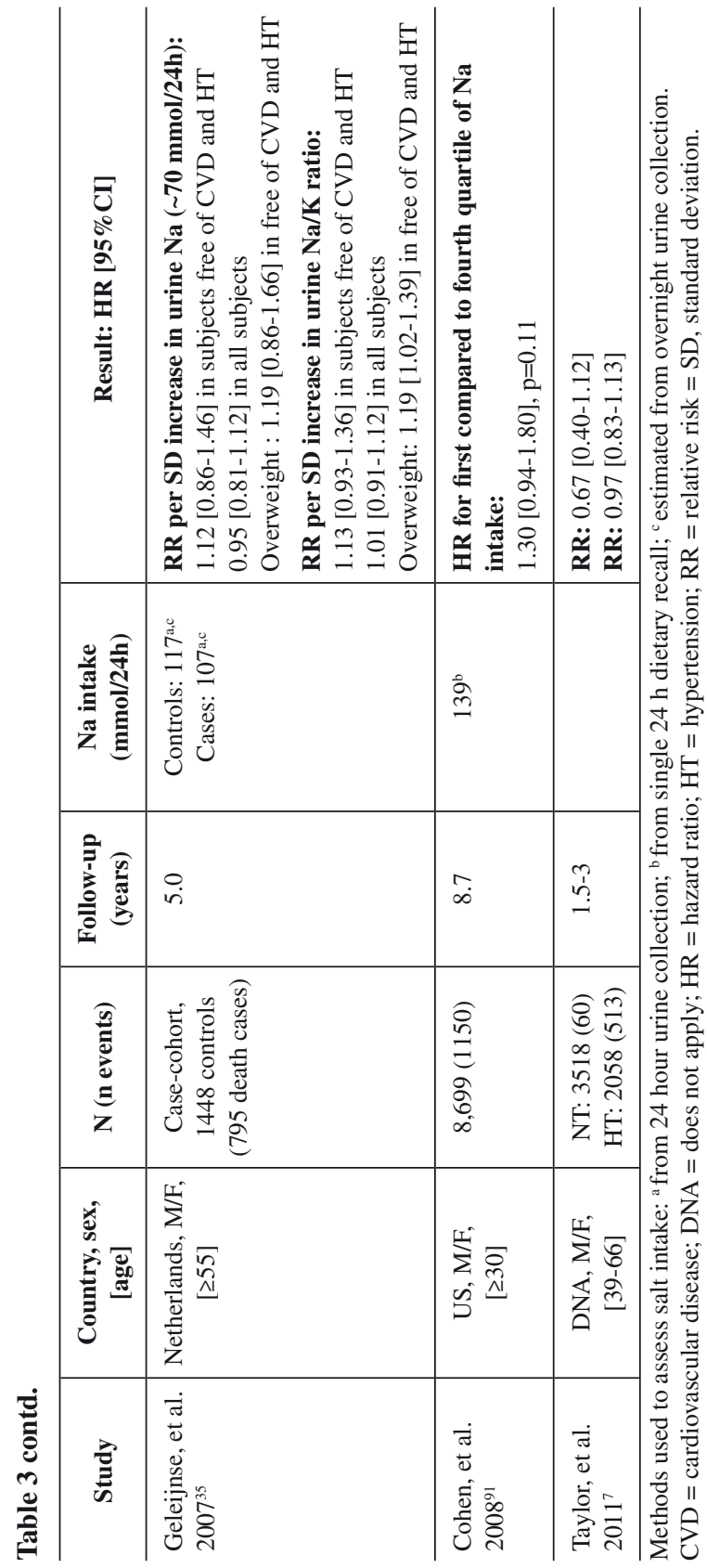




\section{DIETARY SALT INTAKE AND OVERALL MORTALITY}

The Trials of Hypertension Prevention (TOHP), phase I ( $\mathrm{n}=744)$ and II $(n=2382)$ provide the first experimental evidence that link interventions aiming at reducing dietary sodium to all-cause mortality in humans. ${ }^{32} \mathrm{TOHP}$ I and II interventions included persons with pre-hypertension (defined as a mean diastolic blood pressure of $80-89 \mathrm{~mm} \mathrm{Hg}$ without antihypertensive medication) and lasted for 18 and 26-48 months, respectively, with subsequent observational follow-up for cardiovascular outcomes for about 15 and ten years, respectively. ${ }^{32}$ At the end of the interventions, net sodium reductions were $44 \mathrm{mmol} / 24 \mathrm{~h}$ and $33 \mathrm{mmol} / 24 \mathrm{~h}$ in TOHP I and II, respectively. ${ }^{32}$ Participants in the sodium reduction arm experienced a nonsignificant 20 percent lower all-cause mortality as compared to persons in the control group (hazard ratio: 0.80; 95\%CI: $0.51-1.26$ ). ${ }^{20}$ As only 67 deaths occurred during follow-up, power to detect a small reduction in mortality was low. ${ }^{32}$ In a randomized controlled trial conducted in Taiwan among 1981 Veterans (mean age: 75 years), the group assigned to potassiumenriched salt had a non-significant ten percent lower all-cause mortality (age-adjusted hazard ratio: 0.90; 95\%CI: 0.79-1.06) after a median follow-up of 2.6 years compared to the controlled group assigned to regular salt. ${ }^{33} \mathrm{~A}$ recent systematic Cochrane review by Taylor, et al. ${ }^{7}$ on the effects of randomized controlled trials of at least six months duration (that included the two TOHP trials and three other trials) showed that reducing dietary salt intake led to a non-significant decrease in cardiovascular mortality. The risk ratio for all-cause mortality of reduced salt intake was $0.67(0.40-1.12)$ in 3,818 normotensive participants (60 deaths) and 0.97 (0.83-1.13) in 2,058 hypertensive participants (513 deaths). ${ }^{7}$

A few prospective observational studies analyzed the association of dietary sodium intake and all-cause mortality ${ }^{34-38}$ (Table 3 ). In the study by Tuomilehto, et al. ${ }^{38}$ high dietary sodium intake was positively associated with 32 percent increased all-cause mortality in men. The association with all-cause mortality was only observed in overweight men. ${ }^{38}$ Two other studies found some evidence of such a relationship in overweight individuals only. ${ }^{35,36}$ In the Scottish Heart Health Study, there was no evidence of an association between dietary sodium intake and all-cause mortality, ${ }^{37}$ but the analyses were only adjusted for age.

In the National Health and Nutrition Examination Survey (NHANES I) Epidemiologic Follow-up Study, there was an inverse association between urinary sodium excretion and all-cause mortality. ${ }^{34}$ By contrast, a direct association between sodium/calorie ratio was observed with all-cause mortality. ${ }^{34}$ This study however suffers from important methodological flaws. ${ }^{39}$ 
Additional data are required to better delineate the specific contributions of sodium, potassium, magnesium and calcium intakes. The data published so far do not provide a clear and definitive answer, but suggest that the benefit of dietary sodium reduction on overall mortality is likely modest but may be larger in overweight persons. ${ }^{35,36,38}$ These results are important considering that blood pressure and cholesterol explain about 45 percent of the increased risk of coronary heart disease observed in overweight and obesity. ${ }^{40}$

\section{DIETARY SALT INTAKE AND CARDIOVASCULAR DISEASE}

In a randomized controlled trial conducted in Taiwan among 1,981 Veterans (mean age: 75 years), the group assigned to potassium-enriched salt had 41 percent lower cardiovascular mortality (age-adjusted hazard ratio: 0.59; 95\% CI: 0.37-0.95) after a median follow-up of 2.6 years compared to the controlled group assigned to regular salt. ${ }^{33}$

Data from the TOHP I $(n=744)$ and TOHP II $(n=2382)$ trials represent the first experimental evidence to link interventions aiming at reducing dietary sodium and cardiovascular disease incidence in humans. ${ }^{32}$ Participants in the sodium reduction arm experienced a significant 30 percent lower incidence of cardiovascular disease (defined as myocardial infarction, stroke, coronary artery bypass graft, percutaneous transluminal coronary angioplasty or death with a cardiovascular cause) as compared to participants in the control group (hazard ratio: 0.70; 95\%CI: 0.53-0.94). ${ }^{32}$ In the above-mentioned Cochrane meta-analysis of randomized controlled trials of reduced salt intake of at least six months duration, Taylor, at al. ${ }^{7}$ found non-significant relative risk reductions for cardiovascular disease events of 0.71 (95\%CI: 0.42-1.20) in normotensive and 0.84 (95\%CI: 0.571.23) in hypertensive participants. He and $\mathrm{McGregor}^{8}$ re-analysed the data after pooling normotensive and hypertensive participants and found salt reduction to be associated with a significant 20 percent reduction in the risk of cardiovascular disease events (relative risk: 0.80; 0.64-0.99).

A few prospective observational studies analyzed the association of dietary sodium intake and cardiovascular disease mortality ${ }^{34-38}$ (Table 4). Results are inconsistent as two studies ${ }^{36,38}$ found a positive association between dietary sodium intake and cardiovascular mortality, in particular in overweight subjects, whereas other studies found no such association. ${ }^{34,35}$ In the Scottish Heart Health Study, a positive association between dietary sodium intake and coronary deaths was found in women, but not in men. ${ }^{37}$ In the NHANES I Epidemiologic Follow-up Study, a negative association 


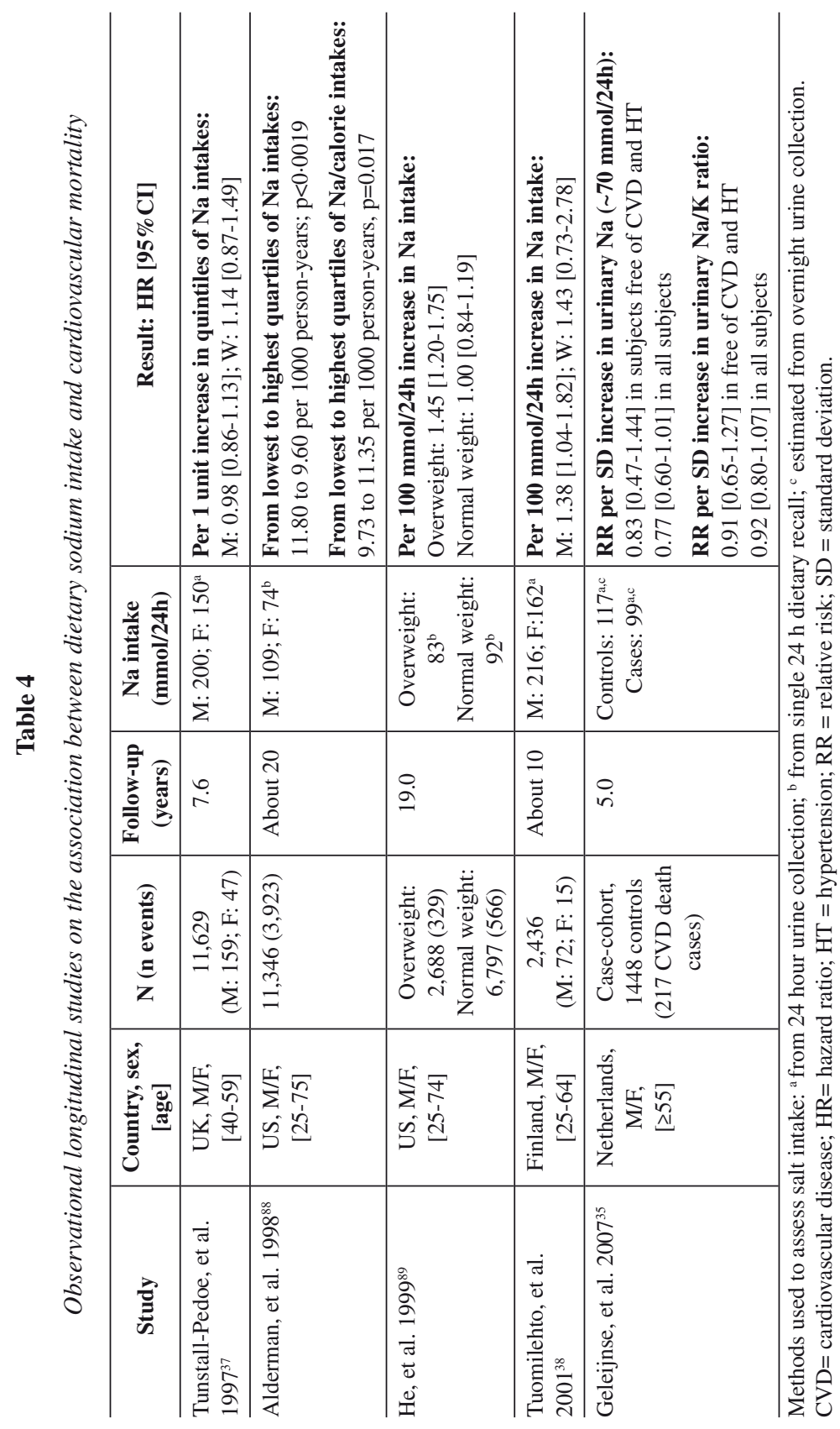


was found between dietary salt intake and cardiovascular mortality, but the association was positive when using sodium/calorie ratio. ${ }^{34}$ However, as stated earlier, this latter study suffers from important methodological flaws. ${ }^{39}$ Further data are needed to clarify this issue. Strazzullo, et al., conducted a meta-analysis which found a significant positive association of higher compared to lower salt intake with incident cardiovascular disease (relative risk: 1.17 ; 95\%CI: 1.02;1.32). ${ }^{41}$

In the New York City Worksite Blood Pressure Study conducted among 2,937 treated hypertensive patients, increased dietary salt intake, assessed using 24-hour urine collection, was associated with decreased incidence of myocardial infarction (relative risk: 0.68 ; 95\%CI: $0.46-0.91$ for a 66 $\mathrm{mmol} / 24 \mathrm{~h}$ reduction in urinary sodium excretion). ${ }^{42} \mathrm{~A}$ limitation of this study is that participants were advised to avoid high sodium food for five days before the 24-hour urine collection. ${ }^{42}$

\section{DIETARY SALT INTAKE AND STROKE}

There is no experimental data linking dietary salt intake to stroke.

With respect to observational studies, several cohorts analyzed the association of dietary sodium intake with the risk of stroke (Table 5). ${ }^{36,38,43-}$ ${ }^{46}$ The data gathered so far are inconsistent, as some studies found a positive association between dietary sodium intake and stroke incidence, ${ }^{36,45}$ whereas others did not $35,38,43,44,46$ Two studies ${ }^{35,38}$ estimated dietary sodium intake using 24-hour urine collection, the others used either a 24-hour recall or a food frequency questionnaire at baseline. The study by Tuomilehto, et al. ${ }^{38}$ found a non-significant positive association between 24-hour urinary sodium excretion and stroke incidence ((hazard ratio: 1.23; 95\% CI: $0.94-1.62$ ) or a $100 \mathrm{mmol} / 24 \mathrm{~h}$ increase in dietary sodium intake, without adjustment for SBP), but as few events occurred ( $\mathrm{n}=84)$, this study may have been underpowered to analyze this specific relationship. Strazzullo, et al., conducted a meta-analysis which found a significant positive association of higher compared to lower salt intake with stroke (relative risk: 1.23 ; 95\%CI: $1.06-1.43$ ) ${ }^{41}$

Ecologic data support a direct association between high sodium intake and stroke mortality ${ }^{47-49}$ the latter being considered as a major marker of hypertension prevalence. 


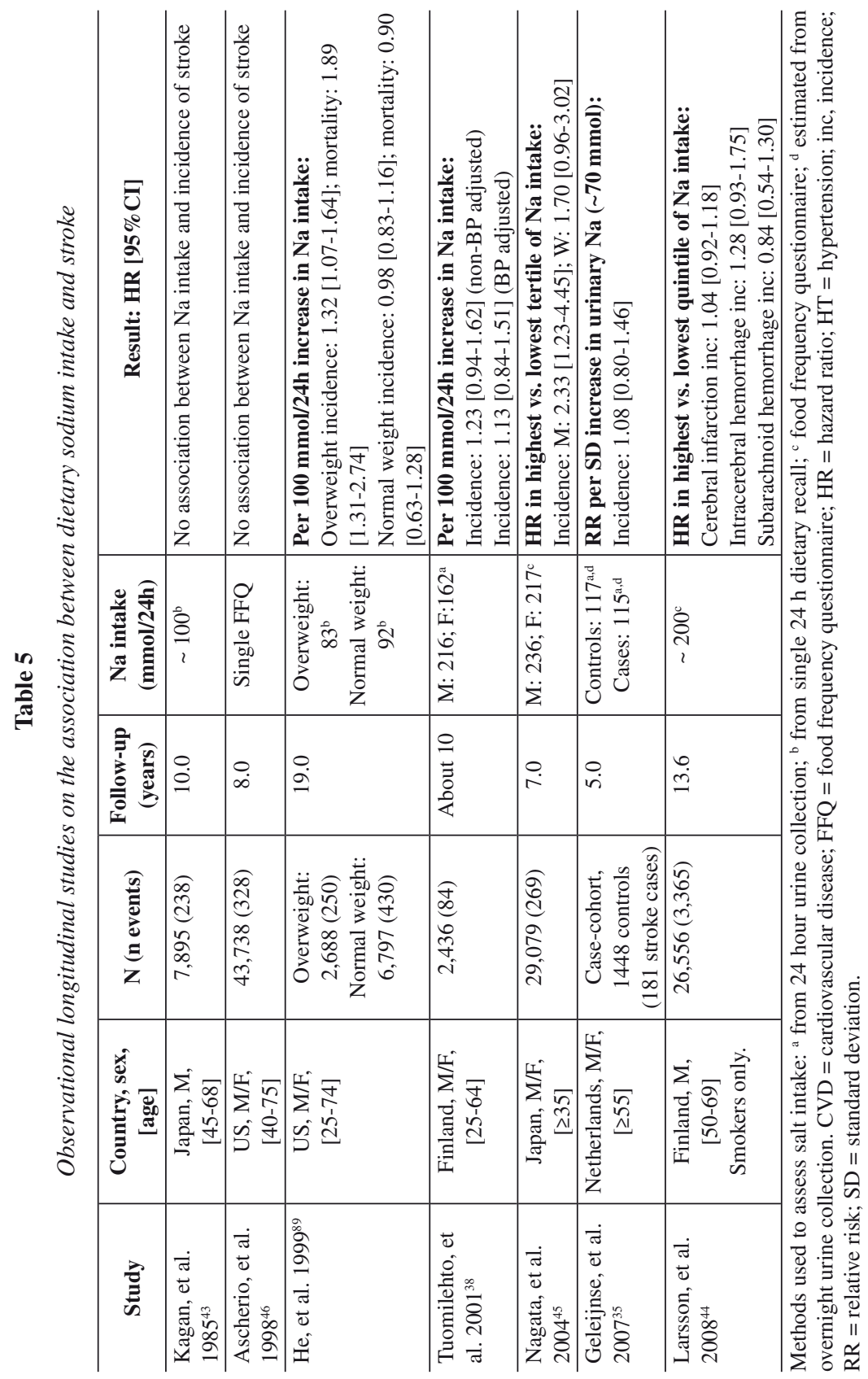




\section{DIETARY SALT INTAKE AND LEFT-VENTRICULARHYPER- TROPHY}

Left-ventricular hypertrophy is a target organ damage associated with increased cardiovascular morbidity and mortality. ${ }^{50-52}$ Sodium consumption has been linked to the presence of left ventricular hypertrophy in adults, ${ }^{53}$ in children and adolescents. ${ }^{54}$ Some evidence suggests that reducing dietary sodium intake results in regression of left ventricular hypertrophy, independently of blood pressure level. ${ }^{55,56}$

\section{CURRENT RECOMMENDATIONS IN VIEW OF THE EXISTING CONTROVERSY}

Despite the ongoing controversy, we consider that recommendations to lower dietary salt intake in the general population are justified because of: (1) the strong link between salt intake and blood pressure, with stronger effect in older people and in hypertensive patients in a context of population ageing; (2) the existence of some experimental evidence that modest reduction in salt intake is beneficial in the absence of experimental evidence that it is harmful; (3) the need to put more emphasis on cost-effective preventive measures in a world in which most people (and countries) cannot afford expensive medicine and treatment.

\section{TOOLS AND STRATEGIES TO REDUCE DIETARY SALT INTAKE}

The average salt intake in most populations considerably exceeds the recommended values. Although the direct association between excessive salt intake and overall or cardiovascular deaths is still a matter of discussion, the benefit of salt reduction via reduced blood pressure and cardiovascular events is likely and several countries have started to implement populationbased strategies to reduce salt intake. ${ }^{4}$ Such decisions took into account the fact that the probability of doing harm is low or non-existent, that high salt intake is also likely associated with diseases other than cardiovascular disease (such as stomach cancer, ${ }^{57,58}$ obesity $^{59}$ and osteoporosis ${ }^{60}$ ) and that this strategy is considered as one of the most cost-effective public health strategies worldwide. .11,12,61 $^{2}$

Salt reduction should be conducted at both the industry and the consumer levels. At the industry level, the most efficient measure is legislation restricting the salt content of selected foods. This approach has 
been suggested to be ten to twenty times more (cost) effective than voluntary reductions in United States ${ }^{11}$ and in Australian modelling studies. ${ }^{62}$ If legislation on specific foods is to be produced, previous knowledge of the main sources of dietary salt intake is needed.

Regulation of food marketing, with restrictions on the content, volume and timing of advertisements or the inclusion of messages on healthy diet (as it currently occurs in France) is another possibility, ${ }^{63}$ although its effect might vary according to the educational or economical level of the target population. ${ }^{64}$ The voluntary engagement of some food manufacturers in health-promoting marketing initiatives is remarkable, but its public health impact remains to be assessed. ${ }^{65}$ Agreements with the food and catering industry towards voluntary reductions of the salt content of selected food items could be achieved, ${ }^{66}$ although, in some countries, the commitments obtained were rather permissive and allowed food companies to circumvent the stated intents. ${ }^{67}$

A tax on salty foods has also been proposed, although the food industry can partly compensate the resulting increased cost by decreased production costs or profit margins, which may have an adverse effect regarding the consumption of other foods. ${ }^{68}$

A better strategy is a targeted food tax combined with an appropriate subsidy on healthy foods such as fruits and vegetables. ${ }^{69}$ Improved food labelling could also help, namely regarding salt and not sodium content, as most consumers are unable to convert sodium into salt values. ${ }^{70}$ The reduction in salt content should be made progressively and in the long term, so that consumers are unaware of the changes. Finally, all these changes should also take into account possible limitations of salt reduction in food processing. ${ }^{71}$

At the consumer level, information campaigns should be initiated and maintained, as they can effectively change dietary behaviour. ${ }^{72,73}$ Although public relations and community-based educational activities might achieve the same effect as a paid advertising campaign, the effect of the latter rapidly vanishes once the campaign ends. ${ }^{73}$ Further, the costs of a paid advertising campaign might be very small compared to the financing of (non-healthy) food advertising (USD \$26 billion per year in the US, ${ }^{74} \mathrm{CHF}$ 331 million in Switzerland ${ }^{75}$ ). It will also be diluted in the large number of (unhealthy) food advertisements present either on television ${ }^{76}$ or on print media. ${ }^{77}$ Hence, the use of a paid advertising campaign might not be very cost-effective.

Nutrition education at school is another possibility, but its effect on behaviour appears to be limited. ${ }^{78}$ An interesting alternative would be the 
use of tailored computer interventions as suggested elsewhere,$^{79}$ but their cost might be too high and their impact at the population has not been adequately assessed.

Finally, a study conducted in France ${ }^{80}$ showed that, regarding food and vegetable consumption, the costs per life-year saved are lower for information campaign (EUR €3,000), followed by Value-Added Tax (VAT) reduction (EUR €99,000) and food stamp policy (EUR €403,000). However, the information campaign would save fewer life-years than VAT reduction. The food stamp policy could reduce health inequalities between lowincome consumers and others, whereas the opposite effect would occur for the other scenarios.

\section{CONCLUSIONS}

There is a strong agreement among experts that average population dietary salt intake should be reduced, targeting the levels recommended by WHO, namely, less than $5 \mathrm{~g}$ per day. With the exception of the historical examples of Finland and Japan, there is no recent data from countries that have implanted population-based strategies to lower dietary salt intake such as the United Kingdom to give a signal that they are going from $10 \mathrm{~g} /$ day to 5 g/day.

The main aim of this reduction is to affect a substantial decline in cardiovascular morbidity and mortality. A careful analysis of the available literature shows however that the epidemiological evidence is still incomplete and that the size of the benefit of such a reduction is still debated. The best evidence is indirect and rests on the observation that reducing salt intake lowers blood pressure. There is also recent direct evidence that reducing salt intake reduces the incidence of cardiovascular disease. While there is some experimental evidence that reducing salt intake could benefit people, there is no experimental evidence that modest reduction in dietary salt intake would harm people.

The controversy mainly rests on observational longitudinal data mostly based on a single baseline estimation of dietary salt intake in the presence of substantial inter-individual variability in salt intake. Several countries have therefore adopted public health policies aiming at reducing salt intake in the general population. The relevant tools and strategies are directed to both the food industry and the consumers. At the industry level, the most efficient measure is legislation on the salt content of selected foods, an approach more (cost) effective than voluntary reductions. At the consumer level, information campaigns, nutrition education at school and tailored 
computer interventions are possible, but costly and with likely limited impact. None of the interventions aiming at reducing salt intake has been rigorously evaluated. Thus, any intervention in this field should be accompanied by an appropriate monitoring and evaluation program conducted in the population, gathering data and producing information on the reduction in salt intake, the impact on blood pressure and, finally, on the level of cardiovascular morbidity and mortality.

\section{Acronyms List:}

NHANES $=$ National Health and Nutrition Examination Survey

TOHP $=$ Trials of Hypertension Prevention

VAT $=$ Value-Added Tax

Acknowledgements: Murielle Bochud is supported by the Swiss School of Public Health Plus (SSPH+).

Conflicts of Interest: None declared.

\section{REFERENCES}

1. Law MR, Frost CD, Wald NJ. By how much does dietary salt reduction lower blood pressure? III--Analysis of data from trials of salt reduction. BMJ. 1991;302:819-24.

2. World Health Organization. The global burden of disease: 2004 update. Geneva, Switzerland: WHO; 2004.

3. World Health Organization. Creating an enabling environment for populationbased salt reduction strategies: report of a joint technical meeting held by WHO and the Food Standards Agency, United Kingdom. Geneva, Switzerland: WHO Press; 2010.

4. Webster JL, Dunford EK, Hawkes C, Neal BC. Salt reduction initiatives around the world. J Hypertens. 2011;29:1043-50.

5. Taubes G. The (political) science of salt. Science. 1998;281:898-901,903-7.

6. Stolarz-Skrzypek K, Kuznetsova T, Thijs L, Tikhonoff V, Seidlerova J, Richart T, et al. Fatal and nonfatal outcomes, incidence of hypertension, and blood pressure changes in relation to urinary sodium excretion. JAMA. 2011;305: $1777-85$.

7. Taylor RS, Ashton KE, Moxham T, Hooper L, Ebrahim S. Reduced dietary salt for the prevention of cardiovascular disease. Cochrane Database Syst Rev. 2011(7):CD009217.

8. He FJ, MacGregor GA. Salt reduction lowers cardiovascular risk: meta-analysis of outcome trials. Lancet. 2011;378:380-2.

9. Forte JG, Miguel JM, Miguel MJ, de Padua F, Rose G. Salt and blood pressure: a community trial. J Hum Hypertens. 1989;3:179-84. 
10. Staessen J, Bulpitt CJ, Fagard R, Joossens JV, Lijnen P, Amery A. Salt intake and blood pressure in the general population: a controlled intervention trial in two towns. J Hypertens. 1988;6:965-73.

11. Bibbins-Domingo K, Chertow GM, Coxson PG, Moran A, Lightwood JM, Pletcher MJ, et al. Projected effect of dietary salt reductions on future cardiovascular disease. N Engl J Med. 2010;362:590-9.

12. Asaria P, Chisholm D, Mathers C, Ezzati M, Beaglehole R. Chronic disease prevention: health effects and financial costs of strategies to reduce salt intake and control tobacco use. Lancet. 2007;370:2044-53.

13. Brown IJ, Tzoulaki I, Candeias V, Elliott P. Salt intakes around the world: implications for public health. Int J Epidemiol. 2009;38:791-813.

14. Ambard L, Beaujard E. Causes de l'hypertension artérielle. Arch Gen Med. 1:520-33.

15. Allen FM. Arterial hypertension. J Am Med Assoc. 1920;74:652.

16. Kempner W. Treatment of hypertensive vascular disease with rice diet. Am J Med. 1948;4:545-77.

17. Dahl LK. Possible role of salt intake in the development of arterial hypertension. In: Cottier P, Bock DK, editors. Essential Hypertension, an International Symposium. Berlin: Springer-Verlag; 1960.

18. Froment A, Milton H, Gravier C. Relationship of sodium intake and essential hypertension. Rev Epidemiol Sante Publique. 1979;27:437-54.

19. Intersalt: an international study of electrolyte excretion and blood pressure. Results for 24 hour urinary sodium and potassium excretion. Intersalt Cooperative Research Group. BMJ. 1988;297:319-28.

20. Frost CD, Law MR, Wald NJ. By how much does dietary salt reduction lower blood pressure? II--Analysis of observational data within populations. BMJ. 1991;302:815-8.

21. Zhao L, Stamler J, Yan LL, Zhou B, Wu Y, Liu K, et al. Blood pressure differences between northern and southern Chinese: role of dietary factors: the International Study on Macronutrients and Blood Pressure. Hypertension. 2004;43:1332-7.

22. Machnik A, Neuhofer W, Jantsch J, Dahlmann A, Tammela T, Machura K, et al. Macrophages regulate salt-dependent volume and blood pressure by a vascular endothelial growth factor-C-dependent buffering mechanism. Nat Med. 2009;15:545-52.

23. Guyton AC. Renal function curve--a key to understanding the pathogenesis of hypertension. Hypertension. 1987;10:1-6.

24. Guyton AC. Dominant role of the kidneys and accessory role of whole-body autoregulation in the pathogenesis of hypertension. Am J Hypertens. 1989;2:575-85.

25. Guyton AC, Coleman TG, Cowley AV, Jr., Scheel KW, Manning RD, Jr., Norman RA, Jr. Arterial pressure regulation. Overriding dominance of the kidneys in long-term regulation and in hypertension. Am J Med. 1972;52:584-94. 
26. Kimura G, Brenner BM. A method for distinguishing salt-sensitive from nonsalt-sensitive forms of human and experimental hypertension. Curr Opin Nephrol Hypertens. 1993;2:341-9.

27. Johnson RJ, Rodriguez-Iturbe B, Nakagawa T, Kang DH, Feig DI, HerreraAcosta J. Subtle renal injury is likely a common mechanism for salt-sensitive essential hypertension. Hypertension. 2005;45:326-30.

28. Johnson RJ, Schreiner GF. Hypothesis: the role of acquired tubulointerstitial disease in the pathogenesis of salt-dependent hypertension. Kidney Int. 1997;52:1169-79.

29. Johnson RJ, Rodriguez-Iturbe B, Kang DH, Feig DI, Herrera-Acosta J. A unifying pathway for essential hypertension. Am J Hypertens. 2005;18:431-40.

30. Lifton RP. Molecular genetics of human blood pressure variation. Science. 1996;272:676-80.

31. Meneton P, Jeunemaitre X, de Wardener HE, MacGregor GA. Links between dietary salt intake, renal salt handling, blood pressure, and cardiovascular diseases. Physiol Rev. 2005;85:679-715.

32. Cook NR, Cutler JA, Obarzanek E, Buring JE, Rexrode KM, Kumanyika SK, et al. Long term effects of dietary sodium reduction on cardiovascular disease outcomes: observational follow-up of the trials of hypertension prevention (TOHP). BMJ. 2007;334:885-8.

33. Chang HY, Hu YW, Yue CS, Wen YW, Yeh WT, Hsu LS, et al. Effect of potassium-enriched salt on cardiovascular mortality and medical expenses of elderly men. Am J Clin Nutr. 2006;83:1289-96.

34. Alderman MH, Cohen H, Madhavan S. Dietary sodium intake and mortality: the National Health and Nutrition Examination Survey (NHANES I). Lancet. 1998;35:781-5.

35. Geleijnse JM, Witteman JC, Stijnen T, Kloos MW, Hofman A, Grobbee DE. Sodium and potassium intake and risk of cardiovascular events and all-cause mortality: the Rotterdam Study. Eur J Epidemiol. 2007;22:763-70.

36. He J, Ogden LG, Vupputuri S, Bazzano LA, Loria C, Whelton PK. Dietary sodium intake and subsequent risk of cardiovascular disease in overweight adults. JAMA. 1999;282:2027-34.

37. Tunstall-Pedoe H, Woodward M, Tavendale R, A'Brook R, McCluskey MK. Comparison of the prediction by 27 different factors of coronary heart disease and death in men and women of the Scottish Heart Health Study: cohort study. BMJ. 1997;315:722-9.

38. Tuomilehto J, Jousilahti P, Rastenyte D, Moltchanov V, Tanskanen A, Pietinen P, et al. Urinary sodium excretion and cardiovascular mortality in Finland: a prospective study. Lancet. 2001;357:848-51.

39. Poulter NR. Dietary sodium intake and mortality: NHANES. The Faculty 31 st International Society and Federation of Cardiology 10-day Teaching Seminar in Cardiovascular Disease, Epidemiology and Prevention. National Health and Nutrition Examination Survey. Lancet. 1998;352:987-8. 
40. Bogers RP, Bemelmans WJ, Hoogenveen RT, Boshuizen HC, Woodward M, Knekt P, et al. Association of overweight with increased risk of coronary heart disease partly independent of blood pressure and cholesterol levels: a meta-analysis of 21 cohort studies including more than 300000 persons. Arch Intern Med. 2007;167:1720-8.

41. Strazzullo P, D'Elia L, Kandala NB, Cappuccio FP. Salt intake, stroke, and cardiovascular disease: meta-analysis of prospective studies. BMJ. 2009; 339:b4567.

42. Alderman MH, Madhavan S, Cohen H, Sealey JE, Laragh JH. Low urinary sodium is associated with greater risk of myocardial infarction among treated hypertensive men. Hypertension. 1995;25:1144-52.

43. Kagan A, Popper JS, Rhoads GG, Yano K. Dietary and other risk factors for stroke in Hawaiian Japanese men. Stroke. 1985;16:390-6.

44. Larsson SC, Virtanen MJ, Mars M, Mannisto S, Pietinen P, Albanes D, et al. Magnesium, calcium, potassium, and sodium intakes and risk of stroke in male smokers. Arch Intern Med. 2008;168:459-65.

45. Nagata C, Takatsuka N, Shimizu N, Shimizu H. Sodium intake and risk of death from stroke in Japanese men and women. Stroke. 2004;35:1543-7.

46. Ascherio A, Rimm EB, Hernan MA, Giovannucci EL, Kawachi I, Stampfer MJ, et al. Intake of potassium, magnesium, calcium, and fiber and risk of stroke among US men. Circulation. 1998;98:1198-204.

47. Sasaki S, Zhang XH, Kesteloot H. Dietary sodium, potassium, saturated fat, alcohol, and stroke mortality. Stroke. 1995;26:783-9.

48. Yamori Y, Liu L, Mizushima S, Ikeda K, Nara Y. Male cardiovascular mortality and dietary markers in 25 population samples of 16 countries. J Hypertens. 2006;24:1499-505.

49. Yamori Y, Nara Y, Mizushima S, Sawamura M, Horie R. Nutritional factors for stroke and major cardiovascular diseases: international epidemiological comparison of dietary prevention. Health Rep. 1994;6:22-7.

50. Levy D, Garrison RJ, Savage DD, Kannel WB, Castelli WP. Prognostic implications of echocardiographically determined left ventricular mass in the Framingham Heart Study. N Engl J Med. 1990;322:1561-6.

51. Verdecchia P, Porcellati C, Reboldi G, Gattobigio R, Borgioni C, Pearson TA, et al. Left ventricular hypertrophy as an independent predictor of acute cerebrovascular events in essential hypertension. Circulation. 2001;104:2039-44.

52. Verdecchia P, Schillaci G, Borgioni C, Ciucci A, Gattobigio R, Zampi I, et al. Prognostic significance of serial changes in left ventricular mass in essential hypertension. Circulation. 1998;97:48-54.

53. Schmieder RE, Messerli FH, Garavaglia GE, Nunez BD. Dietary salt intake. A determinant of cardiac involvement in essential hypertension. Circulation. 1988;78:951-6.

54. Daniels SD, Meyer RA, Loggie JM. Determinants of cardiac involvement in children and adolescents with essential hypertension. Circulation. 1990; 82:1243-8. 
55. Ferrara LA, de Simone G, Pasanisi F, Mancini M. Left ventricular mass reduction during salt depletion in arterial hypertension. Hypertension. 1984; 6:755-9.

56. Liebson PR, Grandits GA, Dianzumba S, Prineas RJ, Grimm RH, Jr., Neaton JD, et al. Comparison of five antihypertensive monotherapies and placebo for change in left ventricular mass in patients receiving nutritional-hygienic therapy in the Treatment of Mild Hypertension Study (TOMHS). Circulation. 1995;91:698-706.

57. Tsugane S. Salt, salted food intake, and risk of gastric cancer: epidemiologic evidence. Cancer Sci. 2005;96:1-6.

58. Dias-Neto M, Pintalhao M, Ferreira M, Lunet N. Salt intake and risk of gastric intestinal metaplasia: systematic review and meta-analysis. Nutr Cancer. 2010;62:133-47.

59. He FJ, Marrero NM, MacGregor GA. Salt intake is related to soft drink consumption in children and adolescents: a link to obesity? Hypertension. 2008;51:629-34.

60. Cappuccio FP, Kalaitzidis R, Duneclift S, Eastwood JB. Unravelling the links between calcium excretion, salt intake, hypertension, kidney stones and bone metabolism. J Nephrol. 2000;13:169-77.

61. Barton P, Andronis L, Briggs A, McPherson K, Capewell S. Effectiveness and cost effectiveness of cardiovascular disease prevention in whole populations: modelling study. BMJ. 2011;343:d4044.

62. Cobiac LJ, Vos T, Veerman JL. Cost-effectiveness of interventions to reduce dietary salt intake. Heart. 2010;96:1920-5.

63. Kelly B, King L, Bauman A, Smith BJ, Flood V. The effects of different regulation systems on television food advertising to children. Aust $\mathrm{N} \mathrm{Z} \mathrm{J}$ Public Health. 2007;31:340-3.

64. Adams J, Tyrrell R, Adamson AJ, White M. Socio-economic differences in exposure to television food advertisements in the UK: a cross-sectional study of advertisements broadcast in one television region. Public Health Nutr. 2011;15:1-8.

65. Adams J, Tyrrell R, White M. Do television food advertisements portray advertised foods in a 'healthy' food context? Br J Nutr. 2011;105:810-5.

66. Klaus D, Bohm M, Halle M, Kolloch R, Middeke M, Pavenstadt H, et al. [Restriction of salt intake in the whole population promises great long-term benefits]. Dtsch Med Wochenschr. 2009;134:S108-18.

67. Hebden L, King L, Kelly B, Chapman K, Innes-Hughes C. Industry selfregulation of food marketing to children: reading the fine print. Health Promot J Austr. 2010;21:229-35.

68. Mytton O, Gray A, Rayner M, Rutter H. Could targeted food taxes improve health? J Epidemiol Community Health. 2007;61:689-94.

69. Nnoaham KE, Sacks G, Rayner M, Mytton O, Gray A. Modelling income group differences in the health and economic impacts of targeted food taxes and subsidies. Int J Epidemiol. 2009;38:1324-33. 
70. Grimes CA, Riddell LJ, Nowson CA. Consumer knowledge and attitudes to salt intake and labelled salt information. Appetite. 2009;53:189-94.

71. Grummer J, Schoenfuss TC. Determining salt concentrations for equivalent water activity in reduced-sodium cheese by use of a model system. J Dairy Sci. 2011;94:4360-5.

72. Reger B, Wootan MG, Booth-Butterfield S. Using mass media to promote healthy eating: A community-based demonstration project. Prev Med. 1999; 29:414-21.

73. Reger B, Wootan MG, Booth-Butterfield S. A comparison of different approaches to promote community-wide dietary change. Am J Prev Med. 2000;18:271-5.

74. Elitzak H. Food marketing costs at a glance. Food Reviews: Economic Research Service, United States Department of Agriculture; 2001:47-48.

75. Swiss Pledge, 2010.

76. Adams J, Hennessy-Priest K, Ingimarsdottir S, Sheeshka J, Ostbye T, White M. Food advertising during children's television in Canada and the UK. Arch Dis Child. 2009;94:658-62.

77. Adams J, Simpson E, White M. Variations in food and drink advertising in UK monthly women's magazines according to season, magazine type and socioeconomic profile of readers: a descriptive study of publications over 12 months. BMC Public Health. 2011;11:368.

78. Van Cauwenberghe E, Maes L, Spittaels H, van Lenthe FJ, Brug J, Oppert JM, et al. Effectiveness of school-based interventions in Europe to promote healthy nutrition in children and adolescents: systematic review of published and 'grey' literature. Br J Nutr. 2010;103:781-97.

79. Kroeze W, Werkman A, Brug J. A systematic review of randomized trials on the effectiveness of computer-tailored education on physical activity and dietary behaviors. Ann Behav Med. 2006;31:205-23.

80. Dallongeville J, Dauchet L, de Mouzon O, Requillart V, Soler LG. Increasing fruit and vegetable consumption: a cost-effectiveness analysis of public policies. Eur J Public Health. 2011;21:69-73.

81. Cutler JA, Follmann D, Elliott P, Suh I. An overview of randomized trials of sodium reduction and blood pressure. Hypertension. 1991;17:I27-33.

82. Midgley JP, Matthew AG, Greenwood CM, Logan AG. Effect of reduced dietary sodium on blood pressure: a meta-analysis of randomized controlled trials. JAMA. 1996;275:1590-7.

83. Cutler JA, Follmann D, Allender PS. Randomized trials of sodium reduction: an overview. Am J Clin Nutr. 1997;65:S643S-51.

84. Graudal NA, Galloe AM, Garred P. Effects of sodium restriction on blood pressure, renin, aldosterone, catecholamines, cholesterols, and triglyceride: a meta-analysis. JAMA. 1998;279:1383-91.

85. He FJ, MacGregor GA. Effect of modest salt reduction on blood pressure: a meta-analysis of randomized trials. Implications for public health. J Hum Hypertens. 2002;16:761-70. 
86. He FJ, MacGregor GA. Effect of longer-term modest salt reduction on blood pressure. Cochrane Database Syst Rev. 2004(3):CD004937.

87. He FJ, MacGregor GA. Importance of salt in determining blood pressure in children: meta-analysis of controlled trials. Hypertension. 2006;48:861-9.

88. Alderman MH, Cohen H, Madhavan S. Dietary sodium intake and mortality: the National Health and Nutrition Examination Survey (NHANES I). Lancet. 1998;351:781-5.

89. He J, Ogden LG, Vupputuri S, Bazzano LA, Loria C, Whelton PK. Dietary sodium intake and subsequent risk of cardiovascular disease in overweight adults. JAMA. 1999;282:2027-34.

90. Cohen HW, Hailpern SM, Fang J, Alderman MH. Sodium intake and mortality in the NHANES II follow-up study. Am J Med. 2006;119:275 e7-14.

91. Cohen HW, Hailpern SM, Alderman MH. Sodium intake and mortality follow-up in the Third National Health and Nutrition Examination Survey (NHANES III). J Gen Intern Med. 2008;23:1297-302. 